\title{
Preliminary In Vitro Wear Assessment of Ceramic Cemented Femoral Components Coupled with Polyethylene Menisci
}

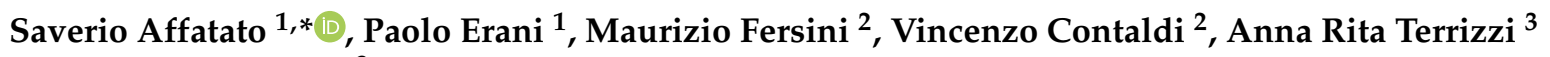 \\ and Antonio Licciulli ${ }^{3}$ \\ 1 Laboratorio di Tecnologia Medica, IRCCS Istituto Ortopedico Rizzoli, 40136 Bologna, Italy; paolo.erani@ior.it \\ 2 SALENTEC s.r.1., 73100 Lecce, Italy; maurizio.fersini@salentec.com (M.F.); \\ vincenzo.contaldi@salentec.com (V.C.) \\ 3 Dipartimento di Ingegneria Dell'Innovazione, Università del Salento, 73100 Lecce, Italy; \\ annarita.terrizzi@unisalento.it (A.R.T.); antonio.licciulli@salentec.com (A.L.) \\ * Correspondence: affatato@tecno.ior.it; Tel.: +39-(051)-636-6864
}

check for updates

Citation: Affatato, S.; Erani, P.; Fersini, M.; Contaldi, V.; Terrizzi, A.R.; Licciulli, A. Preliminary In Vitro Wear Assessment of Ceramic Cemented Femoral Components Coupled with Polyethylene Menisci. Materials 2021, 14, 2112. https://doi.org/10.3390/ ma14092112

Academic Editor: Agnieszka J. Nowak

Received: 16 March 2021

Accepted: 20 April 2021

Published: 22 April 2021

Publisher's Note: MDPI stays neutral with regard to jurisdictional claims in published maps and institutional affiliations.

Copyright: (c) 2021 by the authors. Licensee MDPI, Basel, Switzerland. This article is an open access article distributed under the terms and conditions of the Creative Commons Attribution (CC BY) license (https:// creativecommons.org/licenses/by/ $4.0 /)$.

\begin{abstract}
Success of total knee replacement (TKR) depends on the prosthetic design and materials. The use of metal components is well established with the disadvantage of allergic reactions. Ceramics have been recently proposed because of high wear resistance, excellent biocompatibility, wettability, and suitable mechanical properties. This study was aimed at investigating in vitro wear resistance of Zirconia Toughened Alumina (ZTA)/Ultra-high-molecular-weight polyethylene (UHMWPE) of TKR femoral components. An in vitro protocol was designed with the application of relevant load profile, 6-degrees-of-freedom knee simulator, and $8 \times 10^{5}$ cycles on the ZTA/UHMWPE configuration under bovine calf serum. Before and after wear test, the femoral components were investigated by using the Scanning Electron Microscope (SEM) and the X-Ray Diffraction (XRD) analyses, and stylus surface roughness measurements. The proposed pre-clinical test yielded repeatable results. In particular, gravimetric results showed that, after $8 \times 10^{5}$ cycles, the mean weight loss of the polyethylene mobile components is $5.3 \pm 1.1 \mathrm{mg}$. The surface roughness measurements $\left(\mathrm{Ra}_{\max }\right)$ performed after the wear test showed no significant variation on the UHMWPE menisci. A slight increase of roughness has been found on the ZTA $(0.02 \mu \mathrm{m}$ before wear test, $0.28 \mu \mathrm{m}$ after the test). SEM observations did not show significant modification of the surface morphology. Tetragonal to monoclinic phase ratio was measured by XRD before and after wear test to evaluate stability of tetragonal $\mathrm{ZrO}_{2}$ phase. Minimal conversion of tetragonal to monoclinic phase was found from 5.4 to $8 \%$. Although this study is a preliminary evaluation limited to in vitro tests, it provides novel pre-clinical indications about the potential of ceramic TKR femoral components.
\end{abstract}

Keywords: knee arthroplasty; ceramic composite; X-ray diffractometry; SEM; roughness measurements; knee simulator; bovine calf serum; wear

\section{Introduction}

The knee joint is divided into two different sections: the patella and the tibial-femoral joint. The menisci are in-between them. The main movements of the knee are flexion and extension, a little degree of rotation is allowed also [1]. Knee osteoarthritis (OA), also known as degenerative joint disease, is typically the result of wear and tear and progressive loss of articular cartilage [2]. Typical knee symptoms such as pain and loss of mobility increase as the osteoarthritis progresses. When the symptoms can no longer be satisfactorily alleviated otherwise, the next step is a knee prosthesis implant.

Total knee replacement (TKR) is a common orthopedic surgery that involves replacing the femoral, the tibial component, and a tibial platform/insert/meniscus.

In other words, TKR is a surgical procedure in which an artificial joint or prosthesis replaces a damaged knee joint. The primary indication for TKR is pain, followed by 
functional limitation. Both femoral and tibial components are generally made of cobaltchromium alloys $(\mathrm{CoCr})$, whereas the tibial insert is made of ultra-high-molecular weightpolyethylene (UHMWPE). TKR is one of the most consolidated prosthetic surgeries to give pain relief and restoration of knee function. Many types of prostheses have been used for TKR during the last 40 years. Repeated cycles of failure and development led to fixed or mobile knee prostheses, total or unicondylar femoral components, cemented or cementless systems [3]. Yet this surgery remains one of the most expensive prosthetic surgeries, causing large costs to European countries [4].

Ceramic femoral components may be a viable alternative for all patients with allergies to metals, and may have better wear performance [5-7].

Femoral heads made of alumina ceramics were introduced in 1971 and femoral heads made of zirconia were introduced in 1985 for total hip arthroplasty [8,9]. Alumina ceramics are very interesting in clinical applications for their tribological properties due to their hardness. Some authors suggest that the use of zirconia may improve the mechanical strength of the ball head over alumina [10,11], while others state that zirconia may also reduce polyethylene wear with respect to alumina [12]. Mixed oxides ceramics have been indicated in the literature as a promising compromise between strength and wear requirements. Mixed-oxides ceramic materials can combine the properties of both alumina and zirconia. The addition of zirconia to alumina results in a composite material of increased toughness $[8,13,14]$.

To the authors' knowledge no investigations are available on mixed-oxides ceramics sliding against polyethylene menisci in TKR. Cristofolini and coworkers $[15,16]$ tested the in vitro behavior of ceramic TKR femoral components. In particular, these authors compared the mechanical loosening between ceramic and metal femoral knee components.

The main aim of this work was to develop and validate a pre-clinical protocol to assess the wear behavior of new TKR components. In particular, ZTA knee femoral components were coupled with mobile UHMWPE menisci, and an in vitro protocol was designed to apply a relevant loading profile using a 6-degrees-of-freedom knee simulator for $8 \times 10^{5}$ cycles. The samples were tested using a four-station displacement control knee joint simulator under bovine calf serum. In particular, the question was whether new ceramic knee femoral components would result in less wear than those usually made of metallic alloys. The study was also completed by performing the characterization of the new ceramic components at a microstructural scale (to correlate the composition and structure to the wear behavior) and at a macrostructural scale in order to assess surface morphology, homogeneity, roughness, and stability of such components under cyclic load.

\section{Materials and Methods}

A protocol was properly designed in order to test the ceramic knee femoral components under a cyclic loading onto a knee wear simulator.

\subsection{Test Specimens}

The wear behavior of new TKP mobile bearing configurations was investigated. In particular, three zirconia toughness alumina (ZTA 1, ZTA 2, ZTA 3) femoral components were coupled with three UHMWPE tibial inserts $(1,2,3)$, and a fourth tibial insert was considered as insert soak control (4). The femoral components were CIM (Ceramic Injection Molding) manufactured by the company Salentec s.r.l. (Lecce, Italy); the material is based on $\mathrm{Al}_{2} \mathrm{O}_{3}(83 \% \mathrm{vol})$ and $\mathrm{ZrO}_{2}(17 \% \mathrm{vol})$ and the technological process has been developed in order to get high toughness, full density (up to $99.9 \%$ of theoretical density) sintered parts. The UHMWPE tibial inserts were designed by Salentec and manufactured by using the Computer Numerical Control (CNC DS Meccanica, mod. DS 150, Vicenza, Italy).

A ZTA femoral component with a polyethylene meniscus before the wear test is shown in Figure 1. 


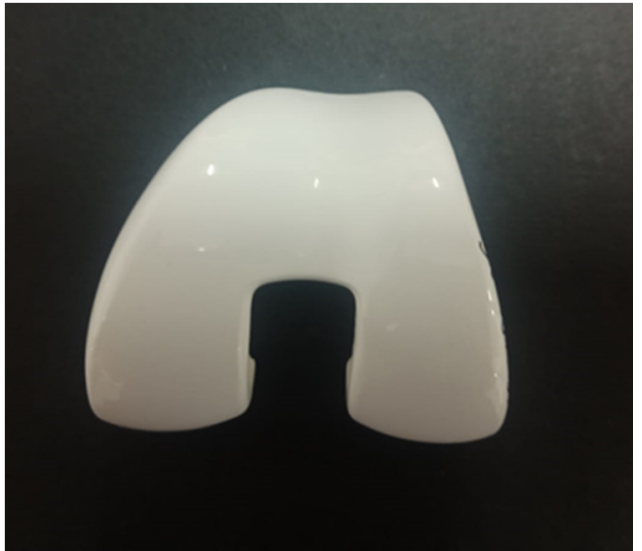

(a)

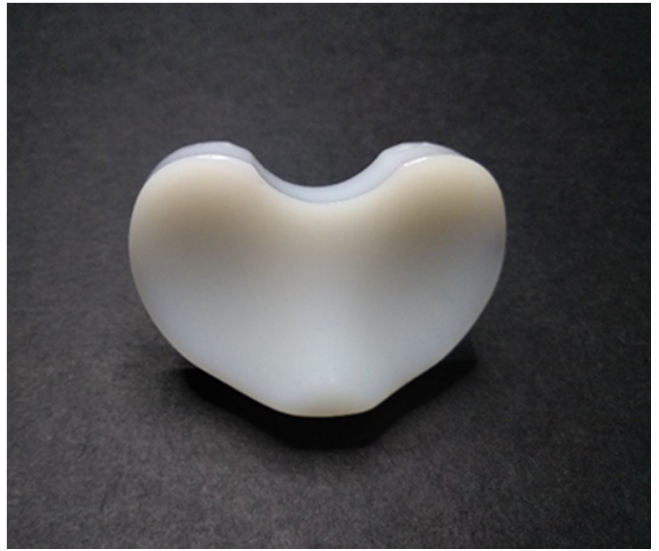

(b)

Figure 1. Zirconia Toughened Alumina (ZTA) femoral component (a) and UHMWPE tibial meniscus (b) before test.

\subsection{Wear Tests}

Wear tests were performed using a four-station knee simulator (Shore Western, Los Angeles, CA, USA) [17-19] as recommended by the International standard ISO 14243 (Implants for surgery-Wear of total knee-joint prostheses). The tibial trays and meniscal bearings were mounted in the lower tilting pools. The load was applied vertically to the tibial tray oscillating between 168 and $2600 \mathrm{~N}$ following a physiological profile. The applied kinematics was in displacement control [20] for the following degrees of freedom:

- flexion/extension angle oscillating between $0^{\circ}$ (neutral) and $58^{\circ}$ (flexion) synchronously with the load;

- $\quad$ anterior/posterior translation oscillating between $0.0 \mathrm{~mm}$ (neutral) and $5.2 \mathrm{~mm}$ (posterior);

- $\quad$ intra/extra rotation oscillating between $2.1^{\circ}$ and $5.7^{\circ}$.

Four UHMWPE tibial components were soaked four weeks prior to the wear tests in order to achieve a steady level of fluid sorption, as recommended by the international standard; the liquid consisting of 25 per cent sterile bovine calf serum (Sigma, St. Louis, $\mathrm{MO}, \mathrm{USA})$ in deionized water; Ethylene-diamine-tetra-acetic acid $\left(20 \mathrm{mmol} / \mathrm{dm}^{3}\right)$ was added to minimize precipitation of calcium phosphates.

After this procedure, the prototypes were tested in the simulator (in dynamic mode) and the last one was used as a reference.

Each station was filled with lubricant (at $37 \pm 2{ }^{\circ} \mathrm{C}$ ), having the same composition as the one used during the soak.

The test duration was set at $8 \times 10^{5}$ cycles. The frequency was set at $1.1 \mathrm{~Hz}$ in the range of ISO 14243-1 recommendations.

Weight loss on tibial menisci $(1,2,3)$ was assessed at $2 \times 10^{5}$ cycle intervals. At each stop the polyethylene tibial components were removed from simulator and cleaned using a detergent at $40^{\circ} \mathrm{C}$ for $10 \mathrm{~min}$. After ultrasonic cleaning in deionized water for $15 \mathrm{~min}$, dried with a nitrogen flow, then dried in vacuum (pressure 0.1 bar) for $40 \mathrm{~min}$. Each meniscus specimen was weighed three times using a semi-microbalance (Sartorius Cubis Mse 225 S-000-DU, Göettingen, Germany) with a sensitivity of $0.01 \mathrm{mg}$ and an uncertainty of $0.01 \mathrm{mg}$. The wear trends determined from the weight loss of each polyethylene samples were corrected by the insert soak control (4). The ZTA femoral components (ZTA 1, ZTA 2, ZTA 3) were weighed before and at the end of the wear test, using an analytical scale (Gibertini E154, Modena, Italy) with a capacity of $150 \mathrm{~g}$ and resolution of $0.1 \mathrm{mg}$.

\subsection{Characterization of Surface Roughness}

Measurements of surface roughness were performed on the worn and unworn ceramic femoral components and tibial menisci in accordance with ISO 7207-2:2011(E) and 
Amd.1:2016(E), which specify the requirements for total and partial knee joint surfaces. A profiler (KLA-Tencor P-16+ / P-6 Profiler, Milpitas, CA, USA) was used.

Profiles were acquired and the maximum roughness $\left(\mathrm{Ra}_{\max }\right)$ was calculated as the average of the three measurements.

The $\mathrm{Ra}_{\max }$ limits for ceramic and tibial components are respectively $0.1 \mu \mathrm{m}$ (with cut-off of $0.25 \mathrm{~mm}$ ) and $2 \mu \mathrm{m}$ (with cut-off of $0.8 \mathrm{~mm}$ ).

\subsection{Surface Morphology Characterization}

Microstructural analyses (surface morphology before and after the wear test) were performed on the bearing couple. In particular, the ceramic femoral components were examined by using scanning the SEM (JEOL JSM IT300LA, Tokyo, Japan); images were acquired by secondary and backscattered electron detectors (accelerating voltage of $10 \mathrm{kV}$, working distances of 11-13 $\mathrm{mm}$ ).

Micrographs of UHMWPE tibial menisci were obtained with optical digital microscopy (Carl Zeiss Microscopy Axio Imager.A2m, Milano, Italy).

\subsection{X-ray Diffractometry}

The tetragonal to monoclinic conversion of zirconia after tribological test was evaluated by diffractometry (Rigaku Model D/MAX ULTIMA, Rigaku Corporation, Tokyo, Japan) comparing ZTA samples extracted from the femoral component before and after wear tests.

The scans were conducted using $\mathrm{Cu}-\mathrm{k} \alpha$ radiation, with a voltage of $40 \mathrm{kV}$ and a current emission of $20 \mathrm{~mA}$, in a range $(\theta-2 \theta)$ between 10 and $90^{\circ}$ with a step size of $0.02^{\circ}$ and acquisition of $2 \mathrm{~s}$ per step.

The monoclinic phase was quantified by the Toraya and Yoshimura method [21]. The fraction $X_{m}$ of monoclinic phase is given by Equation (1):

$$
X_{m}=\frac{I_{m}(\overline{1} 11)+I_{m}(111)}{I_{m}(\overline{1} 11)+I_{m}(111)+I_{t}(101)}
$$

where $I_{m}(\overline{1} 11)$ monoclinic peak intensity $\left(2 \theta \approx 28.2^{\circ}\right), I_{m}(111)$ monoclinic peak intensity $\left(2 \theta \approx 31.3^{\circ}\right), I_{t}(101)$ tetragonal peak intensity $\left(2 \theta \approx 30.2^{\circ}\right)[21,22]$. The intensities were obtained after the baseline subtraction.

\section{Results}

\subsection{Wear Quantitative Evaluation}

All samples completed the wear test without failure. The weight values measured on femoral components before the test $(0$ cycles $)$ and after the test $\left(8 \times 10^{5}\right.$ cycles $)$, are shown in Table 1.

Table 1. Weight and weight loss ( \pm instrumental error) of femoral components.

\begin{tabular}{cccc}
\hline ZTA & \multicolumn{2}{c}{ Weight $\mathbf{( m g )}$} & \multirow{2}{*}{ Weight Loss (mg) } \\
Knee Femoral Components & 0 Cycles & $\mathbf{8} \times \mathbf{1 0}$ Cycles & Wen \\
\hline ZTA \#1 & $126,837 \pm 1$ & $126,831 \pm 1$ & $6 \pm 2$ \\
ZTA \#2 & $128,201 \pm 1$ & $128,192 \pm 1$ & $9 \pm 2$ \\
ZTA \#3 & $126,428 \pm 1$ & $126,418 \pm 1$ & $10 \pm 2$ \\
\hline
\end{tabular}

Instead, each tibial component was weighed three times at $2 \times 10^{5}$ cycle intervals, and the mean values of weight and weight loss measured are shown in Table 2.

It was observed that, at the end of the wear test, the weight loss measured on the ZTA knee components was $5 \pm 2 \mathrm{mg}(0.004 \%$ of initial weight), while the mean mass loss measured on the UHMWPE menisci was $5.3 \pm 1.1 \mathrm{mg}$. 
Table 2. Mean weight and weight loss ( \pm standard deviation) of tibial menisci.

\begin{tabular}{|c|c|c|c|c|c|}
\hline \multirow{2}{*}{ UHMWPE Tibial Menisci } & \multicolumn{4}{|c|}{ Weight (mg) } & \multirow{2}{*}{ Weight Loss (mg) } \\
\hline & 0 Cycles & $2 \times 10^{5}$ Cycles & $4 \times 10^{5}$ Cycles & $8 \times 10^{5}$ Cycles & \\
\hline$\# 1$ & $23,493.3 \pm 0.2$ & $23,484.1 \pm 0.4$ & $23,478.3 \pm 0.03$ & $23,476.7 \pm 0.3$ & $7.7 \pm 1.3$ \\
\hline$\# 2$ & $23,700.1 \pm 0.5$ & $23,695.6 \pm 0.4$ & $23,692.7 \pm 0.1$ & $23,689.9 \pm 0.2$ & $1.4 \pm 1.2$ \\
\hline \#3 & $23,508.9 \pm 1.8$ & $23,501.3 \pm 0.1$ & $23,496.7 \pm 0.01$ & $23,493.4 \pm 0.5$ & $6.7 \pm 0.7$ \\
\hline
\end{tabular}

\subsection{Surface Roughness}

The roughness $\left(\operatorname{Ra}_{\max }\right)$ measured at 0 cycles is well below the limit imposed by the ISO 7207-2 standard requirements.

The roughness measurement $\left(\operatorname{Ra}_{\max }\right)$ was evaluated at $8 \times 10^{5}$ cycles in the area where there was the highest contact pressure, and results are shown in Table 3.

Table 3. Mean femoral and tibial specimens' roughness ( \pm standard deviation).

\begin{tabular}{ccc}
\hline \multirow{2}{*}{ Specimens } & \multicolumn{2}{c}{ Roughness $(\boldsymbol{\mu m})$} \\
\cline { 2 - 3 } & 0 Cycles & $\mathbf{8} \times \mathbf{1 0}^{\mathbf{5}}$ Cycles \\
\hline ZTA Femoral Component & $0.021 \pm 0.004$ & $0.3 \pm 0.1$ \\
UHMWPE Tibial Meniscus & $0.20 \pm 0.04$ & $0.17 \pm 0.06$ \\
\hline
\end{tabular}

The surface roughness on the ZTA parts at $8 \times 10^{5}$ cycles exhibited a slight increase (from $0.02 \mu \mathrm{m}$ before wear test to $0.28 \mu \mathrm{m}$ after the test); no significant variation was observed on the UHMWPE meniscus.

\subsection{Surface Morphology Characterization}

Micrographs of femoral condyle before and after wear test are shown in Figure 2. The surface morphology of the worn sample is almost similar to the unworn one, although there are some grooves due to the wear process, as also confirmed by the measured roughness after test. Some scratches present before and after wear tests have been ascribed to the action of polishing coarser abrasives granules during the manufacturing process.
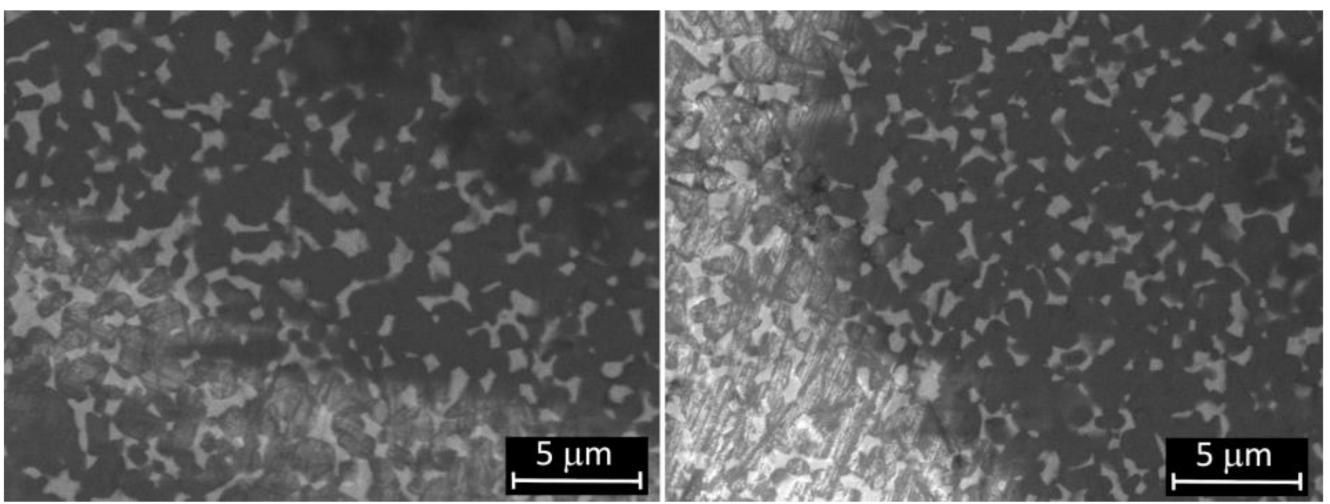

Figure 2. SEM micrographs of ZTA femoral surface before (left) and after (right) the test.

Polyethylene menisci were examined by visual and microscopic inspection. Figures 3 and 4 show UHMWPE meniscus before and after test where scratches are evident on the surface of the sample after wearing cycles. Since the inspected ZTA femoral part is not altered by wear, it is unlikely that ceramic debris are formed during the test. Scratches are therefore attributed to the friction between ceramic and polyethylene. 

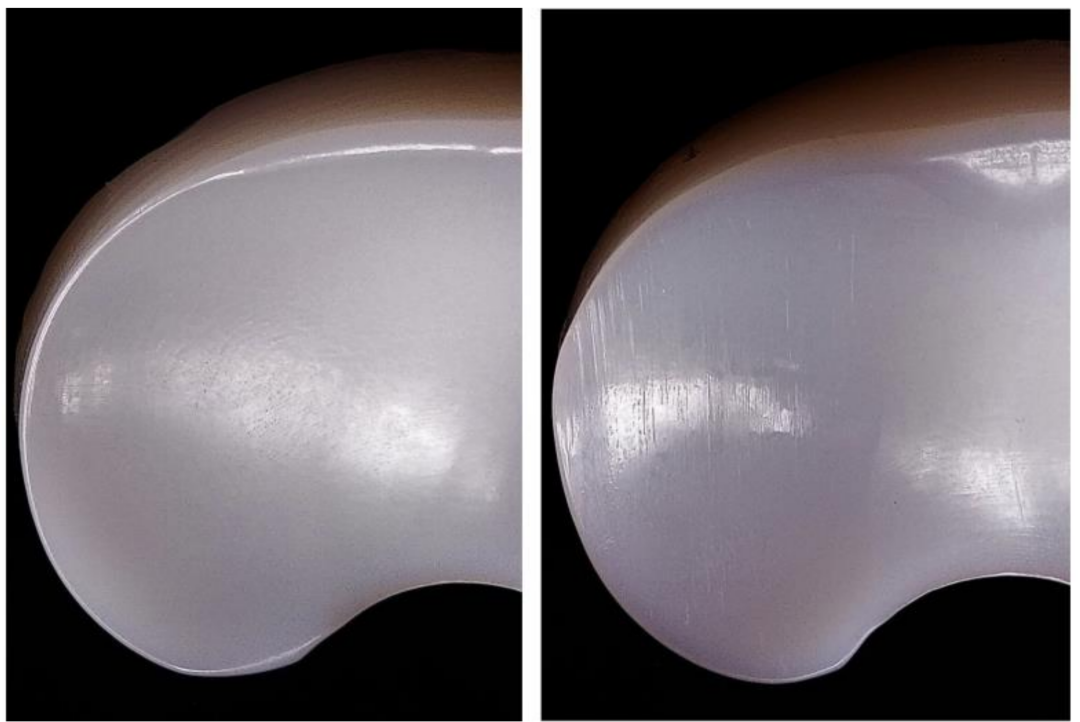

Figure 3. UHMWPE meniscus before (left) and after (right) the test.
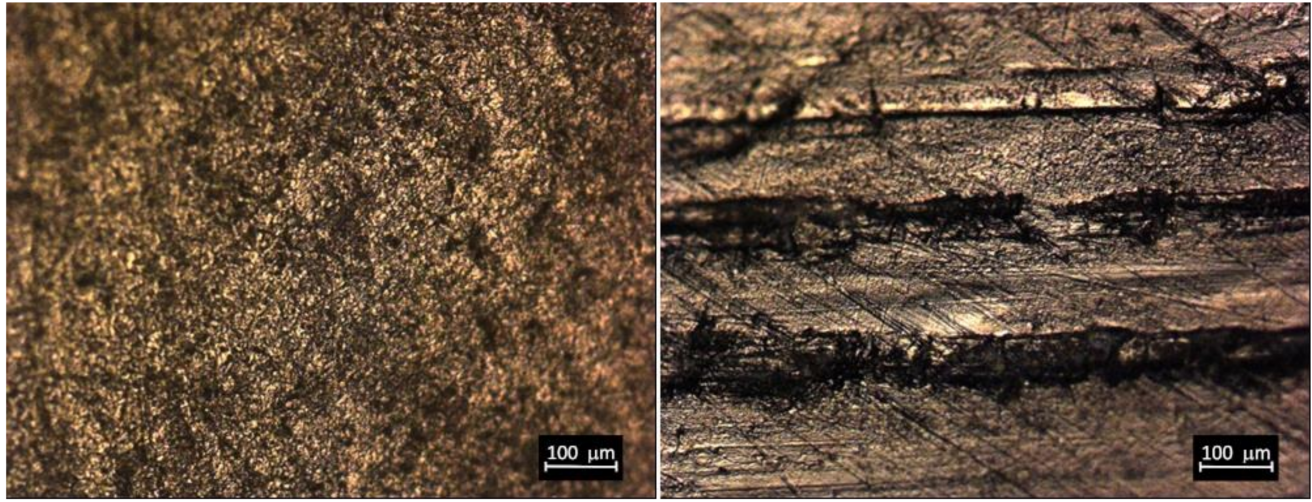

Figure 4. Micrographs of UHMWPE surface before (left) and after (right) the test (zoom 10X).

\subsection{X-ray Diffractometry Results}

Tetragonal phase destabilization on the surface of zirconia and ZTA with consequent formation of monoclinic phase is at the origin of the embrittlement of the components [23]. Tetragonal-to-monoclinic polymorphic transformation in ZTA femoral parts have been evaluated from XRD spectra.

The amount of monoclinic zirconia was quantified on the three samples before and after wear test to evaluate the stability of the tetragonal phase for ZTA under the test conditions. In Table 4 the percentage of monoclinic phase ranges from 5.4 (before test) to $8 \%$ (after test).

Table 4. Mean monoclinic zirconia content ( \pm instrumental error) in ZTA femoral component.

\begin{tabular}{cc}
\hline Wear Test & \% Monocline Phase \\
\hline Before Wear Test & $5.4 \pm 0.3$ \\
\hline After Wear Test & $8.0 \pm 0.4$ \\
\hline
\end{tabular}

The XRD spectra are shown in Figure 5. A slight increase of intensity is evident in the monoclinic peaks $\left(2 \theta \approx 28.2^{\circ}\right.$ and $\left.2 \theta \approx 31.3^{\circ}\right)$ in the worn ZTA components, vice versa, a decrease in the intensity of the tetragonal phase peak $\left(2 \theta \approx 30.2^{\circ}\right)$ is measured (with respect to the components before the wear test). 


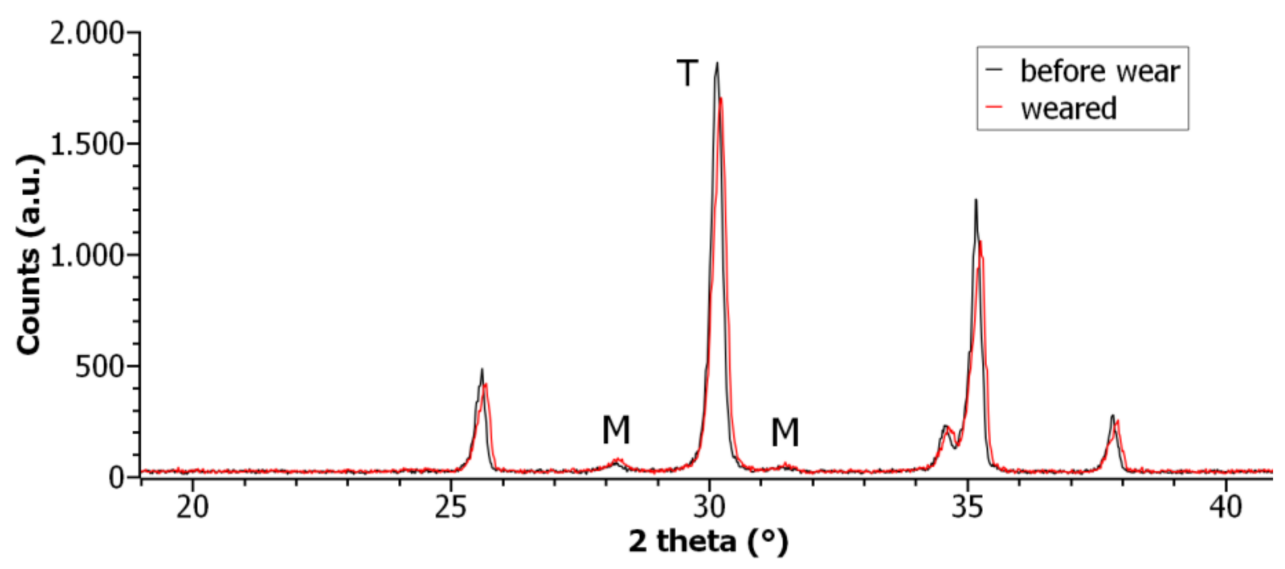

Figure 5. X-ray diffractograms obtained for ZTA femoral component.

\section{Discussion}

Wear behavior of ZTA knee femoral components coupled with mobile UHMWPE menisci is the focus of this study. The samples were tested using a knee joint simulator under bovine calf serum and cyclic load, to establish if ceramic femoral components could exhibit a lower wear than those made of metal alloys usually used for TKR.

Ceramic femoral components did not exhibit relevant wear as proven by absence of weight loss and SEM analyses. X-Ray diffractometry have relieved a minimal conversion of tetragonal to monoclinic zirconia phase: diffractograms show a decrease in the intensity of the tetragonal phase peak and a slight increase of intensity in the monoclinic peaks in the worn ZTA components with respect to the components before the wear test. The total phase change is not relevant to compromise characteristics and mechanical properties (mechanical strength and toughness) of the prostheses.

A real comparison is not possible because there are very few studies referred to ZTA ceramic knee components coupled with UHMWPE menisci. Zietz et al. [6] tested ceramic materials on knee simulator following the standard ISO 14243 and non-significant variation of roughness was measured on UHMWPE meniscus surface, as results found in this study. Cristofolini and coworkers [15], in order to explore the idea of introducing a ceramic TKR femoral component and prevent the risks of a possible clinical failure, developed an experimental protocol to evaluate implant-bone fixation.

The investigations performed in this study showed that the wear rate of the UHMWPE insert coupled with ZTA femoral components is less than metallic femoral components previously tested on the same knee wear simulator. Comparing the obtained results of this work with state of art in metallic knee femoral components coupled with UHMWPE, Affatato et al. [17] tested metallic knee femoral components against UHMWPE obtained a mean mass loss of $20.1 \mathrm{mg}$. The same author, in another work [24], investigated the wear behavior of mobile and fixed bearings, tested for 5 million cycles using bovine calf serum as lubricant and using the same simulator. It was found that mobile designs components showed lower weight losses than the fixed components but greater if compared with current results of this study. In a previous work, Jaber et al. [25] compared the wear behavior of total knee metallic femoral components coupled with UHMWPE menisci, simulating highly demanding daily load waveform, and found a mass loss, after 0.8 million cycles, greater of about $50 \%$ of the results obtained in the this work. In addition, Affatato and coworkers [26] tested small and large sized-mobile inserts (samples \#2 and \#6 respectively) on the same knee wear simulator for 2 million cycles, using bovine calf serum as lubricant. The results emphasized that the larger size (sample \#6) had almost twice the weight loss with respect to the smaller one. Although consistent literature on TKR wear tests became available in recent years, to the authors' knowledge, there are not many reports describing in detail both the wear performances of implants with different designs, tested with the same knee simulator. 
Therefore, it is possible to emphasize from Table 2 that the gravimetric mass loss obtained in this study on the UHMWPE menisci is lower than the results of the previous discussed wear tests with metallic femoral component against UHMWPE menisci under bovine calf serum as lubricant and using the same knee simulator.

The present study obviously has some limitations. The first is that results found are based on a small number of specimens. The second is the fact that the ceramic knee components were compared only with metallic commercial knee prostheses. However, it represents a preliminary approach to understand wear behavior. Further clinical investigations are required to establish whether these differences in wear would result in different long-term outcomes.

\section{Conclusions}

Femoral knee implant plays a key role on ultra-high molecular weight polyethylene (UHMWPE) wear rates. In this work, ZTA femoral components wear and tribological properties have been investigated.

ZTA/UHMWPE were tested using a four-station knee simulator. The set up was used to simulate a 0.8 million walking cycles and provide a comprehension of TKR kinematics over time and relevant loading conditions. The test and investigations showed that the wear rate of the UHMWPE insert coupled with ZTA femoral components is extremely low compared to similar studies on metal femoral components. Not only the wear rate but also the modification of ZTA surface microstructure is negligible, as revealed by SEM and XRD.

This study underlines the excellent wear performances of ZTA/ UHMWPE TKR and opens up new perspectives on the use of ceramic materials for knee replacements.

Future investigations will be focused to analyze if the fixed or mobile knee prosthesis could have significant effects on the wear of UHMWPE inserts.

Author Contributions: S.A. and M.F.-conceived and designed the experiments; M.F.—designed the ceramic knee femoral components and menisci specimens; S.A. and P.E.-performed the in vitro experiment; M.F., V.C., A.R.T., A.L.-performed the Roughness measurements, Microscopy characterization (SEM; digital microscopy), X-ray diffractometry and analyzed the obtained results; S.A.-wrote the initial draft. All authors have read and agreed to the published version of the manuscript.

Funding: This research has been financed by MiSE - HORIZON 2020 PON I\&C 2014-2020, Prog. $\mathrm{n}$. F/050427/01-02/X32.

Institutional Review Board Statement: Not applicable.

Informed Consent Statement: Not applicable.

Data Availability Statement: Data is contained within the article.

Acknowledgments: The authors thank Petroceramics S.p.A. for the support in sintering process.

Conflicts of Interest: The authors declare no conflict of interest.

\section{References}

1. Traina, F.; de Fine, M.; Affatato, S. Antomy of the knee and suitable prostheses. In Wear of Orthopaedic Implants and Artificial Joints; Affatato, S., Ed.; Woodhead Publishing in Materials Series; Woodhead Publishing: Sawston, UK, 2012; pp. 115-132.

2. Nazari, G. Knee osteoarthritis. J. Physiother. 2017, 63, 188. [CrossRef]

3. Song, E.-K.; Seon, J.-K.; Moon, J.-Y.; Ji, Y. The Evolution of Modern Total Knee Prostheses. In Arthroplasty-Update; IntechOpen: London, UK, 2013.

4. Development of a New Generation of Knee Prostheses with Enhanced Lifespan Features Using Advanced Computational Biomechanics I TOTAL.KNEE Project I FP7 I CORDIS I European Commission. Available online: https:/ / cordis.europa.eu/project/ $\mathrm{id} / 303861 /$ it (accessed on 20 December 2020).

5. Bergschmidt, P.; Bader, R.; Mittelmeier, W. Metal hypersensitivity in total knee arthroplasty: Revision surgery using a ceramic femoral component-A case report. Knee 2012, 19, 144-147. [CrossRef]

6. Zietz, C.; Lange, R.; Bergschmidt, P.; Mittelmeier, W.; Bader, R. Third-Body Abrasive Wear of Tibial Polyethylene Inserts Combined with Metallic and Ceramic Femoral Components in a Knee Simulator Study. Int. J. Artif. Organs 2013, 36, 47-55. [CrossRef] 
7. Bergschmidt, P.; Bader, R.; Ganzer, D.; Hauzeur, C.; Lohmann, C.; Rüther, W.; Tigani, D.; Rani, N.; Prats, F.L.; Zorzi, C.; et al. Ceramic Femoral Components in Total Knee Arthroplasty-Two Year Follow-Up Results of an International Prospective MultiCentre Study. Open Orthop. J. 2012, 6, 172-178. [CrossRef]

8. Zietz, C.; Kluess, D.; Bergschmidt, P.; Haenle, M.; Mittelmeier, W.; Bader, R. Tribological Aspects of Ceramics in Total Hip and Knee Arthroplasty. Semin. Arthroplast. 2011, 22, 258-263. [CrossRef]

9. Merola, M.; Affatato, S. Materials for Hip Prostheses: A Review of Wear and Loading Considerations. Materials 2019, 12, 495. [CrossRef]

10. Cuckler, J.M.; Bearcroft, J.; Asgian, C.M. Femoral head technologies to reduce polyethylene wear in total hip arthroplasty. Clin. Orthop. Relat. Res. 1995, 317, 57-63.

11. Callaghan, J.J.; Cuckler, J.M.; Huddleston, J.I.; Galante, J.O. How have alternative bearings (such as metal-on-metal, highly cross-linked polyethylene, and ceramic-on-ceramic) affected the prevention and treatment of osteolysis? J. Am. Acad. Orthop. Surg. 2008, 16, S33-S38. [CrossRef]

12. Toni, A.; Terzi, S.; Sudanese, A.; Tabarroni, M.; Zappoli, A.F.; Stea, S.; Giunti, A. The use of ceramic in prosthetic hip surgery. The state of the art. Chir. Organi Mov. 1995, 80, 13-25.

13. Affatato, S.; Torrecillas, R.; Taddei, P.; Rocchi, M.; Fagnano, C.; Ciapetti, G.; Toni, A. Advanced nanocomposite materials for orthopaedic applications. I. A long-termin vitro wear study of zirconia-toughened alumina. J. Biomed. Mater. Res. Part B Appl. Biomater. 2006, 78, 76-82. [CrossRef]

14. Chevalier, J.; Taddei, P.; Gremillard, L.; Deville, S.; Fantozzi, G.; Bartolomé, J.; Pecharroman, C.; Moya, J.; Diaz, L.; Torrecillas, R. Reliability assessment in advanced nanocomposite materials for orthopaedic applications. J. Mech. Behav. Biomed. Mater. 2011, 4, 303-314. [CrossRef]

15. Cristofolini, L.; Affatato, S.; Erani, P.; Tigani, M.; Viceconti, M. Implant fixation in knee replacement: Preliminary in vitro comparison of ceramic and metal cemented femoral components. Knee 2009, 16, 101-108. [CrossRef] [PubMed]

16. Cristofolini, L.; Affatato, S.; Erani, P.; Leardini, W.; Tigani, D.; Viceconti, M. Long-term implant-bone fixation of the femoral component in total knee replacement. Proc. Inst. Mech. Eng. Part H J. Eng. Med. 2008, 222, 319-331. [CrossRef]

17. Affatato, S.; Leardini, W.; Rocchi, M.; Toni, A.; Viceconti, M. Investigation on Wear of Knee Prostheses Under Fixed Kinematic Conditions. Artif. Organs 2008, 32, 13-18. [CrossRef] [PubMed]

18. Taddei, P.; Modena, E.; Grupp, T.M.; Affatato, S. Mobile or fixed unicompartmental knee prostheses? In-vitro wear assessments to solve this dilemma. J. Mech. Behav. Biomed. Mater. 2011, 4, 1936-1946. [CrossRef] [PubMed]

19. Abdel-Jaber, S.; Belvedere, C.; Leardini, A.; Affatato, S. Wear simulation of total knee prostheses using load and kinematics waveforms from stair climbing. J. Biomech. 2015, 48, 3830-3836. [CrossRef]

20. Affatato, S. Displacement or Force Control Knee Simulators? Variations in Kinematics and in Wear. Artif. Organs 2016, 40, 195-201. [CrossRef]

21. Toraya, H.; Yoshimura, M.; Somiya, S. Calibration Curve for Quantitative Analysis of the Monoclinic-Tetragonal ZrO2System by X-Ray Diffraction. J. Am. Ceram. Soc. 1984, 67, C-119-C-121. [CrossRef]

22. Lopes, A.; Coelho, P.; Witek, L.; Jalkh, E.B.; Gênova, L.; Monteiro, K.; Cesar, P.; Filho, P.L.; Bergamo, E.; Ramalho, I.; et al. Nanomechanical and microstructural characterization of a zirconia-toughened alumina composite after aging. Ceram. Int. 2019, 45, 8840-8846. [CrossRef]

23. Boffelli, M.; Doimo, A.; Marin, E.; Puppulin, L.; Zhu, W.; Sugano, N.; Clarke, I.; Pezzotti, G. Chemically driven tetragonal-tomonoclinic polymorphic transformation in retrieved ZTA femoral heads from dual mobility hip implants. J. Mech. Behav. Biomed. Mater. 2016, 56, 195-204. [CrossRef]

24. Affatato, S.; Bracco, P.; Sudanese, A. In vitro wear assessments of fixed and mobile UHMWPE total knee replacement. Mater. Des. 2013, 48, 44-51. [CrossRef]

25. Jaber, S.A.; Taddei, P.; Tozzi, S.; Sudanese, A.; Affatato, S. In vitro effects on mobile polyethylene insert under highly demanding daily activities: Stair climbing. Int. Orthop. 2014, 39, 1433-1440. [CrossRef]

26. Affatato, S.; Grillini, L.; Battaglia, S.; Taddei, P.; Modena, E.; Sudanese, A. Does knee implant size affect wear variability? Tribol. Int. 2013, 66, 174-181. [CrossRef] 